\title{
Educação Inclusiva: um estudo de caso de um aluno autista na Educação Infantil em Vila Velha - ES
}

\author{
Inclusive Education: a case study of an autistic student in Early Childhood Education in \\ Vila Velha - ES
}

Educación Inclusiva: un estudio de caso de un alumno autista en la Educación Infantil en Vila Velha - ES

Luana Frigulha Guisso ${ }^{1 *}$, Nathália Bermudes Alves da Silva ${ }^{2 *}$.

\begin{abstract}
RESUMO
Objetivo: Apresentar os modos de inclusão do aluno autista no ensino regular em uma instituição de Educação Infantil e o envolvimento da escola neste processo. Detalhamento do caso/Relato da Experiência: É uma pesquisa qualitativa, utilizando o estudo de caso e uma produção de dados a partir da observação, questionário com perguntas abertas aos participantes da comunidade escolar e entrevista com a mãe do aluno. Foi realizada uma pesquisa em uma escola pública no município de Vila Velha - ES, a fim de perceber como se dá o processo de ensino aprendizagem do aluno autista neste ambiente. Considerações finais: Uma nova cultura nas escolas precisa ser construída, a cultura da valorização das diferenças, onde haja a garantia de acesso, a aprendizagem e a participação de todos os alunos dentro da instituição escolar. A presente pesquisa destacou a importância da participação de todos os atores do processo escolar, inclusive dos pais, para que esse processo tenha efetividade.
\end{abstract}

Palavras-chave: Educação Infantil, Educação Inclusiva, Autismo.

\section{ABSTRACT}

Objective: to present the ways of including the autistic student in regular education in an institution of Early Childhood Education and the involvement of the school in this process. Case Detailing / Experience Report: It is a qualitative research, using the case study and a data production from the observation, questionnaire with questions open to the participants of the school community and interview with the student's mother. A study was carried out at a public school in the city of Vila Velha - ES, in order to understand how the learning process of autistic students occurs in this environment. Final Considerations: A new culture in schools needs to be built, a culture of valuing differences, where there is guaranteed access, learning and participation of all students within the school institution. The present research emphasized the importance of the participation of all the actors of the school process, including the parents, so that this process is effective.

Key words: Child Education, Inclusive Education, Autism.

\footnotetext{
${ }^{1}$ Mestrado Profissional em Tecnologia Ambiental pela Faacz Aracruz, Aracruz - ES.

*E-mail: Ifgd10@hotmail.com

${ }^{2}$ Mestrado Profissional em Gestão Social, Educação e Desenvolvimento Regional pela Faculdade Vale do Cricaré (FVC), São Mateus - ES.
}

SUBMETIDO EM: 6/2019

ACEITO EM: 7/2019

PUBLICADO EM: $8 / 2019$ 


\section{RESUMEN}

Objetivo: presentar los modos de inclusión del alumno autista en la enseñanza regular en una institución de Educación Infantil y la participación de la escuela en este proceso. Detalle de caso / Informe de experiencia: es una investigación cualitativa, utilizando el estudio de caso y una producción de datos a partir de la observación, cuestionario con preguntas abiertas a los participantes de la comunidad escolar y entrevista con la madre del alumno. Se realizó una investigación en una escuela pública en el municipio de Vila Velha - ES, a fin de percibir cómo se da el proceso de enseñanza aprendizaje del alumno autista en este ambiente. Consideraciones finales: Una nueva cultura en las escuelas necesita ser construida, la cultura de la valorización de las diferencias, donde haya la garantía de acceso, el aprendizaje y la participación de todos los alumnos dentro de la institución escolar. La presente investigación destacó la importancia de la participación de todos los actores del proceso escolar, incluso de los padres, para que ese proceso tenga efectividad.

Palabras clave: Educación Infantil, Educación Inclusiva, Autismo.

\section{INTRODUÇÃO}

A inclusão escolar no Brasil, situa-se hoje num bom momento considerando toda trajetória percorrida até a implementação das políticas públicas hoje em vigor e as discussões mais embasadas que acontecem atualmente de forma recorrente.

O processo de inclusão é abordado no presente estudo. O retrato atual do cotidiano escolar, as ferramentas utilizadas para que de fato os educandos sejam tratados da mesma maneira, cada um com a sua diferença, o quão os educadores hoje estão ou não preparados para lidar com este tipo de proposta, porque hoje este é um grande desafio, tendo em vista que mesmo com alguns anos de implementação da inclusão nas escolas, os professores trazem a ideia de que não tem preparo e formação para ensinar estes tipos de alunos, já que os alunos com deficiência sempre foram encaminhados para os professores especializados da área, em classes especiais, tendo o diferencial e sendo assim classificados como profissionais aptos a fazêlos aprender (MITTLER P, 2000).

O Transtorno Espectro Autismo (TEA) foi descrito por Leo Kanner em 1943 e Hans Asperger em 1944. Este primeiro identificou uma falta no quesito habilidade das crianças para manterem relações interpessoais e dificuldade com a fala. Em seguida, Asperger incluiu mais alguns pontos, como a falta de capacidade em olhar para o próximo nas trocas sociais (BOSA C, 2002).

Segundo Chicon JF et al. (2016), a inclusão na sala de aula realizada diretamente pelo professor regente, deve considerar a importância de trazer esta temática da diferença/diversidade junto da sala de aula, seja por meio da arte de contação de história, teatro, seja com a participação da família, ou por outros meios, com o objetivo de esclarecer sobre a presença de crianças com deficiência no grupo, trazendo uma aceitação entre eles, compreensão e colaboração, para que desde a infância eles consigam amadurecer a ideia do acolhimento aos diferentes grupos presentes na sociedade.

Dessa forma, o objetivo do estudo é pesquisar como acontece a Educação Inclusiva de um aluno autista no cotidiano do ensino regular da Educação Infantil no município de Vila Velha e o envolvimento da instituição escolar neste processo. São relatadas as intervenções realizadas pela educadora no cotidiano da sala de aula de ensino regular, a atuação da escola neste processo inclusivo com o apoio do Atendimento Educacional Especializado, a relação dos pais do aluno público alvo de educação especial com a escola.

\section{Estudo de caso}

Para começarmos os relatos da vivência, chamaremos o aluno de João e os profissionais por suas respectivas funções. O meu primeiro dia começou efetivamente acompanhando o João na sala de aula regular. Uma característica marcante da professora regente é justamente que a inclusão realizada por ela 
com relação ao aluno é total, através de atividades com músicas, contação de histórias, atividades escritas, entre outras. No laudo médico apresentado pela família não consta qual é o grau do autismo, mas é uma criança independente, se alimenta sozinho, vai ao banheiro acompanhado, compreende o que é dito, obedece aos comandos, mas tem a fala prejudicada.

Quando a professora é questionada sobre como é realizada a inclusão do aluno público alvo da educação especial na sala de aula regular, ela respondeu:

"De forma lúdica, com jogos, brincadeiras, histórias. Criando condições físicas, materiais e ambientais. (...) Dispor de materiais que estimulem o desenvolvimento do raciocínio e funções cognitivas. NUNCA sozinho e fora do grupo. E ter interesse em capacitar essa criança para que ela encare com mais segurança e felicidade o ano seguinte."

Ele recebe acompanhamento integral de cuidadora que é ativa em todo o progresso que ele alcançou até o momento e relatou um pouco do histórico do João. Disse o quanto ele evoluiu com relação ao relacionamento interpessoal.

Durante a rotina de atividades no parquinho, uma criança da mesma idade, jogou areia no João, deixandoo furioso. É importante pontuar que ele assume uma postura de irritabilidade em situações de conflito com os colegas quando algum educador não chama a atenção da criança como ele acha que deveria. Já quando o educador adverte um outro aluno, da mesma forma que faz com ele, a satisfação é visível.

Em um dia de formação dos professores a cuidadora ficou responsável pela sala e resolveu fazer um show de calouros. Alguns alunos quiseram se apresentar e os demais que não quiseram, ficaram como jurados. $O$ João que em um primeiro momento não demonstrou interesse de se apresentar para os colegas, ficou como jurado. Mas, quando viu todos cantando, disse que queria cantar também. Ele cantou "Parabéns a Você", ganhou uma estrelinha e ficou muito feliz ao ser aplaudido pelos amigos.

A ida ao Projeto Tamar foi uma experiência maravilhosa. O João se comportou muito bem, ficou atento as explicações, subiu nas réplicas das tartarugas. Admirou as tartarugas marinhas no aquário, ficou falando "ovo" se referindo aos ovos das tartarugas, foi o "comandante" do navio, lanchou e ao final brincou no parquinho. Foi só encantamento.

Finalizando a vivência na sala de aula de ensino regular, no questionário apresentado a professora regente, traz um questionamento a respeito da opinião pessoal da educadora sobre o que de fato consiste a educação inclusiva, e a sua resposta foi:

"Essa tal de inclusão, penso eu, que seja algo fictício, pois na realidade ela não é vista por parte de alguns educadores como inclusiva, e sim como um problema. (...) Receber estímulos para que possa se sentir importante, que é capaz, que dentro de seus limites ela vai conseguir. (...) Na maioria das instituições de ensino, os profissionais que lidam com essa criança não são capacitados, (...). O educador que realmente se dispõe em fazer o melhor por esse aluno tem que buscar por conta própria." - Professora Regente

\section{Experiências acerca do atendimento educacional especializado (AEE)}

No primeiro dia no Atendimento Educacional Especializado fui muito bem recebida pela professora de educação especial do contraturno. Segundo a professora ele não sabe ler, mas sabe escrever.

Nas atividades reconhece as letras e os números, tem boa coordenação motora fina, gosta de montar quebra cabeça.

A professora explica que ele melhorou muito a concentração, e que antes ficava contrariado quando não conseguia montar um quebra cabeça, por exemplo, mas que hoje, com várias tentativas, ele tem êxito no que se propõe a fazer. Interage bem e consegue se comunicar verbalmente. A professora explica e destaca a importância da professora do ensino regular que inclui de fato este aluno. 
O que percebi durante essa vivência no Atendimento Educacional Especializado (AEE) é que quando o João está em algum espaço com outros alunos, e esses não estão fazendo as atividades e sim brincando, ele começa a ficar inquieto e perde o interesse no que está fazendo.

Vale frisar que o AEE não é o único ambiente com responsabilidade pelas estratégias de ensino a serem adotados pelos alunos público alvo da educação especial no processo de ensino e aprendizagem. Mas nele, é preciso conter uma atuação efetiva entre os professores, a estruturação de redes para ensinar os alunos em todos os cantos da escola, tanto na sala de aula, quando no AEE.

\section{A equipe pedagógica e o entendimento sobre inclusão escolar}

Durante o processo de pesquisa dentro da escola, a equipe pedagógica formada pela diretora, pedagoga e coordenadora disciplinar receberam um questionário com as mesmas perguntas, que tratavam sobre 0 entendimento de ambas sobre o autismo e a inclusão escolar.

Quando falamos sobre os fatores que a escola contribui para o desenvolvimento do trabalho com alunos diagnosticados com TEA, nos deparamos com o ponto de vista de que:

"São grandes os desafios na práxis escolar para auxiliar no avanço educacional do aluno autista. Mas, considero que alguns avanços que favoreçam à inclusão de alunos autistas, na escola de ensino regular, foram atingidos. Reconheço que em sua maioria, esses avanços, ficam à mercê do trabalho individualizado de alguns professores, não sendo uma real política. Fatores que julgo ser de grande importância a esse desenvolvimento educacional do aluno autista, são ações tais como: formações específicas da área; avanço nas políticas públicas que visam garantir os direitos do aluno autista; contratações de profissionais especializados; formação acadêmica específica. " - Coordenadora

\section{As perspectivas dos pais no processo de inclusão escolar}

Desde que iniciei meu processo de observação na escola, a participação ativa dos pais sempre foi um ponto muito elogiado por parte dos professores e equipe pedagógica.

A primeira pergunta que fiz a ela foi a respeito de como ela descobriu o diagnóstico. Ela relatou:

"quando ele tinha 3 anos, ele não falava muito e resolvemos marcar uma consulta com o neurologista da APAE que passou alguns exames, examinou e deu o diagnóstico de Autismo."

A mãe relata não ter tido nenhum problema com relação ao diagnóstico, que só de vê-lo correndo e brincando, já é o suficiente. Diferentemente do que geralmente acontece com a maioria das famílias.

Com relação ao apoio da escola e a contribuição no desenvolvimento, ela disse:

"A escola ajuda em tudo. Antes da escola ele era mais tímido e mais ciumento, depois que entrou na escola começou a conviver com outras crianças e ficar mais "solto"."

E que entendia por Inclusão Escolar o seguinte:

"Quando tem crianças que estudam em escolas assim, elas ficam excluídas, eles não dão a mínima, deixa sentado lá, separado. Não chamam para fazer as atividades com as outras crianças, e aqui eles incluem, tem a professora do AEE que ajuda, todas atividades que ele participa é tudo com as crianças, coreografias, tudinho. $O$ meu filho ele é tratado como toda criança." - Mãe

E de fato o convívio dos alunos público alvo da educação especial na escola, junto com outras crianças, proporciona um efetivo desenvolvimento e evolução, que é notado pela família, que deixa claro que a parceria entre escola e família é imprescindível para a obtenção de bons resultados. 


\section{DISCUSSÃO}

Durante a pesquisa foi importante observar a importância do brincar no ensino tanto dos alunos público alvo da educação especial, quanto dos ditos normais, ideia essa que é corroborada por Falkenbach EMF (1987), que afirma que a iniciativa do brincar também é um exercício de estímulo que precisa partir dos educadores. Ajudar o educando a brincar, é desenvolver a iniciativa e confiança, que são características essenciais para a aprendizagem da criança.

A cuidadora durante a pesquisa afirma que é importante manter o diálogo com o aluno, ao invés de simplesmente tirá-lo do contexto da brincadeira, o que é reforçado pelo pensamento de Bosa C (2002) o ato de isolar as crianças com autismo decorre da incompreensão do que está sendo pedido. Em muitos episódios, essa medida foi usada para não interagir, o que desencadeou rupturas nas possibilidades de interação social. Essa barreira na comunicação prejudica as interações, as práticas pedagógicas e em todos os meios onde essa criança se encontra inserida.

Quando se fala em escolarização, é preciso levar em consideração que existem educandos com diferentes desenvolvimentos e, assim, com tempos diferentes para alcançarem certos conhecimentos e habilidades, gerando a necessidade de se estabelecer estratégias pedagógicas para atender a essa diversidade e garantir a escolarização (BRAUN P; MARIN M, 2013) ou seja, evidenciando as diferenças que podem acontecer diante da aquisição de conhecimento mediada pela escola.

Para que se compreenda melhor todo o processo de escolarização do aluno diagnosticado com alguma deficiência intelectual na escola regular, é importante citar Vygotsky LS (1983), que considera que o desenvolvimento humano se dá nas condições concretas de vida, nos meios sociais, nas relações interpessoais e nos modos de como esses sujeitos são inseridos, independente se tem a deficiência intelectual ou não, trazendo significado de mundo para esse sujeito e favorecendo a sua apropriação cultural.

A equipe pedagógica afirma que a inclusão é possível mas que são necessárias investimentos, e que de fato trará resultados quando houver investimentos em formação inicial e continuada dos educadores que seja capaz de "[...] torná-los capazes de conceber e de ministrar uma educação plural, democrática [...] como são as escolas para todos" (MANTOAN MTE, 2003).

Quando se fala de inclusão escolar, não se pode tratar com uma ação de curto prazo, é preciso que as mudanças sejam feitas aos poucos, que o real significado desse termo seja entendido por todos os que convivem no âmbito escolar. A importância da relação entre família e escola é destacada pela Declaração de Salamanca (Aiello, 2002), e a sintonia entre as partes asseguraria uma participação ativa dos pais desses alunos na tomada de decisão e no planejamento da parte educacional dos seus filhos, com a adoção de uma comunicação aberta. De um modo geral, os pais demonstram em alguns momentos insatisfações com relação a escola, que acabam não atendendo suas expectativas. Entretanto, a maioria dos familiares considera a escola um ambiente que proporciona um desenvolvimento integral dos filhos (GLAT R, 2003).

Assim, este movimento que busca consolidar de fato a educação inclusiva, onde todos os rótulos dados a esses educandos sejam superados e que a segregação de espaços não seja necessária, mas a educação seja comum a todos, pensado para todos e por todos.

O movimento precisa ser dinâmico, de modo que sociedade e escola, educadores e alunos, governos e leis, trabalhem com um mesmo objetivo com o objetivo de suprir todas as necessidades sociais, políticas e educacionais dos sujeitos.

\section{CONSIDERAÇÕES FINAIS}

Constatamos com a presente pesquisa que a educação inclusiva na sala de aula regular dessa escola é presente, a professora regente junto a cuidadora, trabalham com um mesmo objetivo, ampliar ao máximo o desenvolvimento do aluno, o tratando como igual dentro de suas limitações. É muito explorado o aprendizado de forma lúdica, com canções, contação de histórias e atividades que envolvam o imaginário. É possível perceber a evolução diária dele diante dessa inclusão. 


\section{REFERÊNCIAS}

1. AIELLO ALR. Família inclusiva. In: PALHARES, M.S e MARINS, S.C.F. Educação Inclusiva. São Carlos: EdUFSCar, 2002.

2. BOSA C. Autismo: Atuais interpretações para antigas observações. In: BAPTISTA, C. R.; BOSA, C. Autismo e Educação: reflexão e propostas de intervenção. Porto Alegre: Artmed, 2002.

3. BRAUN P, MARIN M. Ensino colaborativo com prática de inclusão escolar. In R. Glat \& M. D. Pletsch, Estratégias educacionais diferenciadas para alunos com necessidades especiais, (pp. 49-64). Rio de Janeiro: EdUERJ, 2013.

4. CHICON JF. et al. Educação Física e Inclusão: A mediação pedagógica do professor na brinquedoteca. Movimento Revista da Escola de Educação Física da UFRGS, v. 22, n. 1, 279-292. Porto Alegre, 2016.

5. FALKEMBACH EMF. Diário de Campo: um instrumento de reflexão. Contexto e Educação. Universidade de ljui. ano 2. no 7,julho /set 1987.p. 19-24.

6. GLAT R. Uma família presente e participativa: o papel da família no desenvolvimento e inclusão social da pessoa com necessidades especiais. Anais do 9 Congresso Estadual das APAES de Minas Gerais, 2003.

7. MANTOAN MTE. Prefácio X. In: Educação inclusiva: contextos sociais. Peter Mittler, Tradução Windyz Bazão Ferreira. Porto Alegre: Artmed, 2003.

8. MITTLER P. Working towards inclusive education: social contexts. Londres: David Fulton, 2000.

9. VYGOTSKY LS. Obras escogidas III: historia del desarrollo de las funciones psíquicas superiores. Madri: Visor, 1983. 